\title{
Restricted selection and effective population size
}

\author{
RP Wei * \\ Department of Forest Genetics and Plant Physiology, Swedish University \\ of Agricultural Sciences, 90183 Umeå, Sweden
}

(Received 22 May 1995; accepted 6 March 1996)

\begin{abstract}
Summary - A simple and flexible selection method, 'restricted truncation selection', has been developed to screen superior individuals from populations with family structure. 'Restricted' means placing limits on the contributions of families to the selected group and on the number of families allowed to contribute. Selection is made on the basis of individual performance judged by phenotype or breeding value estimate. Formulae have been derived to predict the approximate effective population size in the selected group. Changes in the restrictions used modify the distribution of family contributions and thus lead to different effective sizes in the selected population. Effective size is influenced by sib type, heritability, selection intensity, initial family number and size. It is decreased by restrictions on the family number but increased by restrictions on family contributions. The application of the predictions of effective sizes to planning a breeding population is discussed.
\end{abstract}

selection / family / truncation / effective size

Résumé - Sélection avec restriction et effectif génétique. Une méthode de sélection simple et flexible, appelée «sélection par troncature avec restriction», a été mise au point pour retenir les individus supérieurs dans des populations à structure familiale. La restriction revient à imposer des contraintes sur la contribution des familles au groupe sélectionné et sur le nombre de familles autorisées à contribuer. La sélection est basée sur la performance individuelle phénotypique ou sur une estimée de valeur génétique. Des formules approximatives de calcul de l'effectif génétique du groupe sélectionné sont données. Des changements dans les contraintes appliquées modifient la distribution des contributions familiales et conduisent ainsi à des effectifs génétiques différents dans les populations sélectionnées. L'effectif génétique dépend du type de famille, de l'héritabilité, du nombre initial de familles et de leur taille. Cet effectif diminue si on impose des contraintes sur le nombre de familles mais augmente si les contraintes portent sur les contributions familiales. L'application des prédictions d'effectif génétique dans la planification d'expériences de sélection est discutée.

sélection / famille / troncature / effectif génétique

* Correspondence and reprints: Department of Renewable Resources, University of Alberta, Edmonton, AB T6G 2H1, Canada 


\section{INTRODUCTION}

In a population with uniform family structure, selection leads to different families making different contributions to the selected group. Effective population size, if concerning family number (Robertson, 1961), is thus always lower in the selected population than the initial size, except when all families contribute the same numbers of individuals. Reduction of effective population size is an inevitable effect, for example, of truncation selection based on either phenotype or optimal index (Lush, 1947; Robertson, 1961; Burrows, 1984; Falconer, 1989). Wei (1995) has therefore proposed a modified truncation selection method in which restrictions are placed on the number of individuals selected from a family, and also on the number of families from which selections are made. It has been shown that truncation selection with restrictions can be used for the manipulation of both effective size and genetic gain in the selected population (Wei, 1995). This study attempts to increase the general applicability of the method and to derive approximate formulations for predicting the effective size following selection.

\section{ASSUMPTIONS AND SELECTION THEORY}

Consider a group of $m$ unrelated or equally related families, each of $s$ members that are genetically related by the coefficient of relatedness, $r$. The observed phenotypes of all individuals are recorded. The phenotype of the $k$ th individual of the $j$ th family could be expressed as the sum of two independent variables.

$$
x_{j k}=x_{j}+d_{j k}
$$

where $x_{j}$ are family means, and $d_{j k}$ are within-family deviations. If the family means have variance $\sigma_{b}^{2}$ and within-family deviations have variance $\sigma_{w}^{2}$, the total phenotypic variance, $\sigma_{t}^{2}$, is $\sigma_{t}^{2}=\sigma_{b}^{2}+\sigma_{w}^{2}$ and the ratio of the phenotypic variance of family mean to the total phenotypic variance is

$$
K=\sigma_{b}^{2} / \sigma_{t}^{2}
$$

Selection criteria will be the phenotypic value or optimal index that best predicts the breeding value of an individual (Lush, 1947; Falconer, 1989). In the following development the index will be treated in the same way as phenotypic value but with a different value for the ratio $\left(K^{*}\right)$ of the variance of family mean to the total variance given by Wei and Lindgren (1994) in the form

$$
K^{*}=\beta^{2} K /\left[\beta^{2} K+(1-\beta)^{2}(1-K)\right]
$$

where $\beta=(1-K)[1+(s-1) r] /\{[1+(s-1) r](1-2 K)+s K\}$.

A proportion $(P)$ of individuals will be selected. Two restrictions are imposed: one on the maximum number $\left(s_{r}\right)$ of individuals that may be contributed by a family and one on the number $\left(m_{r}\right)$ of families that are allowed to contribute. Thus, the $m_{r}$ top-ranking families with the $s_{r}$ top-ranking individual in each family are shortlisted. Superior individuals are finally truncated from the shortlist, on the basis of phenotypic value or optimal index. 
Let $P_{1}=s_{r} / s$ and $P_{2}=m_{r} / m$, the proportions of the restrictions $s_{r}$ and $m_{r}$ to the family size and number respectively. The extreme cases of restricted selection with specified $P_{1}$ and $P_{2}$ values describe conventional selections and onestep restricted selections as follows (Falconer, 1989; Wei, 1995; Wei and Lindgren, 1996). When both $P_{1}$ and $P_{2}$ are one, selection is based on either phenotypic or optimal index value but is unrestricted. $P_{1}=P$ (and thus $P_{2}=1$ ) describes within-family selection, and $P_{2}=P$ (and thus $P_{1}=1$ ) corresponds to betweenfamily selection. Selection with $P_{1} P_{2}=P$ represents the permutations of combined between-family and within-family truncation. One-step restricted selection means restrictions being imposed on either just family number $\left(P_{2}=1\right)$ or just family contributions $\left(P_{1}=1\right)$.

\section{EFFECTIVE POPULATION SIZE AND APPROXIMATIONS}

Let $n_{j}$ denote the number selected from the $j$ th family and total selections $n=\Sigma n_{j}$. Two types of definitions for effective population size are considered:

$$
N_{\mathrm{R}}=\frac{n^{2}}{\Sigma n_{j}^{2}}=\frac{n^{2}}{m P_{2} E\left(n_{j}^{2}\right)}
$$

and

$$
N_{\mathrm{B}}=\frac{n(n-1)}{r \Sigma n_{j}\left(n_{j}-1\right)}=\frac{n(n-1)}{r m P_{2} E\left[n_{j}\left(n_{j}-1\right)\right]}
$$

where $E\left(n_{j}^{2}\right)$ is the second moment of $n_{j}$ samples and $E\left[n_{j}\left(n_{j}-1\right)\right]$ is the second factorial moment. Both were developed for considering inbreeding effect in offspring ( $N_{\mathrm{R}}$ by Robertson, 1961; $N_{\mathrm{B}}$ by Burrows, 1984 ) although the values may have potential uses in other senses. Considering selfing of selected individuals into random mating, $0.5\left[r / N_{\mathrm{R}}+(1-r) / n\right]$ is the average inbreeding coefficient $(\Delta F)$ of progeny. If selfing is excluded, $0.5 / N_{\mathrm{B}}$ is then the average pairwise coancestry in the selected group relative to the parents of the population, and therefore is the average inbreeding coefficient of progeny produced by random mating among selected individuals.

For planning breeding programmes, breeders often need to predict selection differentials (genetic gain) as well as effective population size by using existing information (eg, $K$ value) and designated operation parameters $\left(m, s, P, P_{1}, P_{2}\right.$ in the present case). Here we proceed in analogy with Burrows (1984) and Wei and Lindgren (1996) to reformulate [1] and [2] to enable the prediction of effective size.

We assume that $U_{j}$ represents the number of individuals in the $j$ th sampled family with performance exceeding the truncation point relative to $P, P_{1}$ and $P_{2}$. Thus, they sum to a random variable and are distributed over integers $0,1, \ldots, s_{r}$. As shown in the Appendix, the required moments of $U_{j}$ are

$$
\begin{aligned}
E\left(U_{j}\right) & =s P \\
E\left(U_{j}^{2}\right)=\frac{s P^{2}\left(s P_{1}-1\right)}{P_{1} N_{r}\left(K, P, P_{1}, P_{2}\right)}+E\left(U_{j}\right) & =s P \frac{s P P_{1}+P_{1} N_{r}\left(K, P, P_{1}, P_{2}\right)-P}{P_{1} N_{r}\left(K, P, P_{1}, P_{2}\right)}
\end{aligned}
$$


and

$$
E\left[U_{j}\left(U_{j}-1\right)\right]=\frac{s P^{2}\left(s P_{1}-1\right)}{P_{1} N_{r}\left(K, P, P_{1}, P_{2}\right)}
$$

where $N_{r}\left(K, P, P_{1}, P_{2}\right)$ stands for the corresponding effective population size under selection from a population of infinitely large family number and size. Let $f(x)$ denote the density function of the family mean $(x)$ in an infinite population, and $p(x)$ the proportion of members selected from a family. Then the term $N_{r}\left(K, P, P_{1}, P_{2}\right)$ is expressed in the integral form (Wei, 1995; Wei and Lindgren, 1991)

$$
N_{r}\left(K, P, P_{1}, P_{2}\right)=\frac{P^{2}}{\int p(x)^{2} f(x) d x}
$$

Clearly $N_{r}\left(K, P, P_{1}, P_{2}\right)$ measures the relative value of effective size compared to that before selection. As $K=0$, selection is completely based on within-family deviations, thus $N_{r}\left(K, P, P_{1}, P_{2}\right)$; as $K=1$, selection is completely based on family means, thus $N_{r}\left(K, P, P_{1}, P_{2}\right)=P / P_{1}$. To obtain $N_{r}\left(K, P, P_{1}, P_{2}\right)$ for $K$ between 0 and 1, numerical computation is needed (for full details see Burrows, 1984; Wei and Lindgren, 1991; Wei, 1995).

In contrast to $U_{j}, n_{j}$ represents a consequence of censorship applied to the population sample. The $n_{j}$ are constrained to sum to $n$ and are distributed over integers $0,1, \ldots, \min \left(s_{r}, n\right)$. Thus we do not directly employ $E\left(U_{j}^{2}\right)$ and $E\left[U_{j}\left(U_{j}-1\right)\right]$ as the respective approximations of $E\left(n_{j}^{2}\right)$ and $E\left[n_{j}\left(n_{j}-1\right)\right]$. Instead, we assume that

$$
E\left(n_{j}^{2}\right)=W E\left(U_{j}^{2}\right)
$$

and

$$
E\left[n_{j}\left(n_{j}-1\right)\right]=V E\left[U_{j}\left(U_{j}-1\right)\right]
$$

in which $W$ and $V$ will be obtained for two cases.

\section{When only $K=0$ is considered}

When $K=0$ there is no difference among families, and selection is based on withinfamily deviations but is random with respect to pedigree. By using $K=0$ as a factor, formulations for predicting effective population sizes have been developed for unrestricted selection and one-step restricted selection (Burrows, 1984; Wei and Lindgren, 1996). Proceeding in a similar way, the relevant hypergeometric sampling moments for the present situation yield

$$
E\left[n_{j}\left(n_{j}-1\right)\right]=\frac{s P\left(s P_{1}-1\right)(m s P-1)}{P_{2}\left(m s P_{1} P_{2}-1\right)}
$$

and

$$
E\left(n_{j}^{2}\right)=\frac{s^{2} P\left(m s P P_{1}+m P_{1} P_{2}-m P-P_{1}\right)}{P_{2}\left(m s P_{1} P_{2}-1\right)}
$$


When $K=0$, [7] yields the same result as [10]. By using $N_{r}\left(K, P, P_{1}, P_{2}\right)=P_{2},[4]$, [7] and [10], $W$ is solved in the form

$$
W=\frac{s P_{1}\left(m s P P_{1}+m P_{1} P_{2}-m P-P_{1}\right)}{\left(m s P_{1} P_{2}-1\right)\left(s P P_{1}+P_{1} P_{2}-P\right)}
$$

Therefore an estimative approximation to [1] is

$$
N_{R 1}=\frac{m P N_{r}\left(K, P, P_{1}, P_{2}\right)\left(m s P_{1} P_{2}-1\right)\left(s P P_{1}+P_{1} P_{2}-P\right)}{P_{2}\left(m s P P_{1}+m P_{1} P_{2}-m P-P_{1}\right)\left[s P P_{1}+P_{1} N_{r}\left(K, P, P_{1}, P_{2}\right)-P\right]}
$$

As [8] yields the same result as [9] at $K=0$, we could obtain

$$
V=\frac{P_{1}(m s P-1)}{P\left(m s P_{1} P_{2}-1\right)}
$$

and

$$
N_{B 1}=\frac{N_{r}\left(K, P, P_{1}, P_{2}\right)\left(m s P_{1} P_{2}-1\right)}{r P_{2}\left(s P_{1}-1\right)}
$$

\section{When both $K=0$ and $K=1$ are considered}

Obtaining the consequences of selection for the special case when $K=1$ is easy. Because $K=1$ means no variation within families, and truncation selection is completely based on family means with family contributions either $P_{1}$ or zero, we have

$$
E\left(n_{j}^{2}\right)=\frac{s^{2} P P_{1}}{P_{2}}
$$

and

$$
E\left[n_{j}\left(n_{j}-1\right)\right]=\frac{s P\left(s P_{1}-1\right)}{P_{2}}
$$

Meanwhile, for infinite populations, $N_{r}\left(K, P, P_{1}, P_{2}\right)=P / P_{1}$. A linear relationship between $W$ and $N_{r}\left(K, P, P_{1}, P_{2}\right)$, which passes the two limiting cases [10] and [15], produces

$$
W=\frac{P_{1} N_{r}\left(K, P, P_{1}, P_{2}\right)-P}{P_{1} P_{2}-P}\left[\frac{s P_{1}\left(m s P P_{1}+m P_{1} P_{2}-m P-P_{1}\right)}{\left(m s P_{1} P_{2}-1\right)\left(s P P_{1}+P_{1} P_{2}-P\right)}-\frac{1}{P_{2}}\right]+\frac{1}{P_{2}}
$$

Thus, [1] could be predicted using

$$
N_{R 2}=\frac{m s P P_{1} N_{r}\left(K, P, P_{1}, P_{2}\right)}{P_{2} W\left[s P P_{1}+P_{1} N_{r}\left(K, P, P_{1}, P_{2}\right)-P\right]}
$$

In the same way, we can obtain the following using [5], [8], [9] and [16]:

$$
V=\frac{P_{1} N_{r}\left(K, P, P_{1}, P_{2}\right)-P}{P_{1} P_{2}-P}\left[\frac{P_{1}(m s P-1)}{P\left(m s P_{1} P_{2}-1\right)}-\frac{1}{P_{2}}\right]+\frac{1}{P_{2}}
$$


and

$$
N_{B 2}=\frac{P_{1} N_{r}\left(K, P, P_{1}, P_{2}\right)(m s P-1)}{r P P_{2} V\left[s P_{1}-1\right]}
$$

\section{RESULTS AND DISCUSSION}

The effective population size following selection illustrates the possible disadvantages (eg, inbreeding depression) of using selection in production populations, and the richness of genetic resources achieved for further selection and breeding. Knowledge of effective size helps a breeder assess the benefits and risks associated with a breeding operation such as selection in planning a breeding programme.

When selection is applied to a breeding population or progeny test, effective population sizes can be calculated directly from pedigrees of selections using [1] and [2]. Before testing, the prediction of effective sizes requires prior knowledge of $K$ and $N_{r}\left(K, P, P_{1}, P_{2}\right)$, except in the extreme cases $P_{1}=P, P_{2}=P$ and $P_{1} P_{2}=P$. To plan an advanced- or improved-generation breeding population, values of $K$ derived from measurements of the last generation could be directly employed. In planning a new breeding programme, a reliable value of $K$ is often not available. Any information about the genetics of the species under consideration can then be used to synthesize $K$, such as data from similar tests in the same or similar environments, or trials at clonal, individual, family (sibs), population, provenance or even species levels in greenhouse, nursery or field conditions. Breeders should use existing knowledge to make the best possible estimate of $K$.

The effective population size, $N_{r}\left(K, P, P_{1}, P_{2}\right)$, from infinite populations is used to draw general conclusions and to predict $N_{\mathrm{R}}$ and $N_{\mathrm{B}}$ from finite populations. For unrestricted selection, $N_{r}\left(K, P, P_{1}, P_{2}\right)$ could be computed using the same procedure as Burrows (1984) and Wei and Lindgren (1991). Truncation points corresponding to $P$ can be obtained or interpolated from existing tables and computational programmes. When restrictions are imposed, the population for selection has truncated distributions of family means and within-family deviations. Searching for a truncation point corresponding to $P, P_{1}$, and $P_{2}$ becomes complicated. A numerical procedure to calculate $N_{r}\left(K, P, P_{1}, P_{2}\right)$ has been documented in previous studies (Wei, 1995; Wei and Lindgren, 1996).

With assumption that family mean and within-family deviations are normally distributed, and the total phenotypic variance is one, an example is given to show $N_{r}\left(K, P, P_{1}, P_{2}\right)$ at $P=0.01$ for different $K, P_{1}$ and $P_{2}$ values (table I). As $K$ increases, effective size rapidly decreases except where $P_{1}=P, P_{2}=P$ and $P_{1} P_{2}=P$. At given $K$ values, the restrictions yield different results, in comparison with unrestricted selection, depending on which type of restriction is used. A restriction on family contributions leads to a more dispersed distribution of selections among families, and thus higher effective size. The trend becomes most evident when $K$ is high and the restriction is strong. In contrast, a restriction on family number drastically reduces effective size, especially at low $K$.

Analysis of predicted effective population sizes for a small population (table II) suggests the same effects. The optimal index selection is, for instance, worse than phenotypic selection in conserving effective size because $K^{*}$ is much higher than 
Table I. Effective population size, $N_{r}\left(K, P, P_{1}, P_{2}\right)$, following restricted selection from infinitely large populations for $P=0.01$ and different $K, P_{1}$ and $P_{2}$ values.

\begin{tabular}{|c|c|c|c|c|c|c|c|c|c|c|c|}
\hline \multirow[t]{2}{*}{$\mathrm{P}_{1}$} & \multirow[t]{2}{*}{$\mathrm{P}_{2}$} & \multicolumn{10}{|c|}{$\mathrm{K}$} \\
\hline & & 0.010 & 0.025 & 0.050 & 0.075 & 0.100 & 0.125 & 0.150 & 0.200 & 0.250 & 0.300 \\
\hline \multirow[t]{6}{*}{1.00} & 1.0 & 0.9320 & 0.8404 & 0.7112 & 0.6057 & 0.5191 & 0.4473 & 0.3875 & 0.2951 & 0.2286 & 0.1797 \\
\hline & 0.50 & 0.4881 & 0.4686 & 0.4346 & 0.4003 & 0.3667 & 0.3346 & 0.3044 & 0.2503 & 49 & 576 \\
\hline & 0.25 & 0.2469 & 0.2418 & 0.2325 & 0.2226 & 0.2123 & 0.2018 & 0.1912 & 0.1702 & 0.1500 & 0.1311 \\
\hline & 0.10 & 0.0994 & 0.0985 & 0.0969 & 0.0951 & 0.0932 & 0.0912 & 0.0892 & 0.0848 & 0.0801 & 0.0752 \\
\hline & 0.05 & 0.0499 & 0.0496 & 0.0492 & 0.0488 & 0.0483 & 0.0479 & 0.0474 & 0.0463 & 451 & 138 \\
\hline & 0.01 & 0.0100 & 0.0100 & 0.0100 & 0.0100 & 0.0100 & 0.0100 & 0.0100 & 100 & 00 & 100 \\
\hline \multirow[t]{5}{*}{0.500} & 1.0 & 0.9320 & 0.8404 & 0.7112 & 0.6057 & 0.5191 & 0.4473 & 0.3875 & 0.2951 & 0.2286 & 0.1800 \\
\hline & 0.50 & 0.4881 & 0.4686 & 0.4346 & 0.4003 & 0.3667 & 0.3346 & 0.3044 & 0.2503 & & 0.1678 \\
\hline & 0.25 & 0.2469 & 0.2418 & 0.2325 & 0.0226 & 0.2123 & 0.2018 & 0.1912 & 0.1702 & 0.1501 & 0.1313 \\
\hline & 0.10 & 0.0994 & 0.0985 & 0.0969 & 0.0951 & 0.0932 & 0.0912 & 0.0892 & 0.0848 & 0.0802 & 0.0755 \\
\hline & 0.05 & 0.0499 & 0.0496 & 0.0492 & 0.0488 & 0.0483 & 0.0479 & 0.0474 & 0.0463 & 0.0453 & 0.0441 \\
\hline \multirow[t]{5}{*}{0.250} & 1.0 & 0.9320 & 0.8404 & 0.7112 & 0.6057 & 0.5191 & 0.4473 & 0.3876 & 0.2961 & 0.2321 & 0.1868 \\
\hline & 0.50 & 0.4881 & 86 & 346 & 03 & 0.3667 & 347 & 0.3046 & 0.2514 & 083 & 0.1745 \\
\hline & 0.25 & 0.2469 & 0.2418 & 0.2325 & 0.0226 & 0.2123 & 0.2019 & 0.1915 & 0.1714 & 0.1532 & 0.1372 \\
\hline & 0.10 & 0.0994 & 0.0985 & 0.0969 & 0.0951 & 0.0933 & 0.0916 & 0.0898 & 0.0864 & 0.0833 & 0.0804 \\
\hline & 0.05 & 0.0499 & 0.0497 & 0.0494 & 0.0492 & 0.0491 & 0.0490 & 0.0488 & 0.0486 & 0.0484 & 0.0482 \\
\hline \multirow[t]{4}{*}{0.100} & 1.0 & 0.9320 & 0.8404 & 0.7112 & 0.6060 & 0.5210 & 0.4531 & 0.3996 & 0.3237 & 0.2739 & 0.2400 \\
\hline & 0.50 & 0.4881 & 0.4686 & 0.4346 & 0.4008 & 0.3692 & 409 & 0.3164 & 0.2765 & 466 & 0.2234 \\
\hline & 0.25 & 0.2469 & 0.2418 & 0.2328 & 0.2242 & 0.2165 & 0.2095 & 0.2033 & 0.1927 & 0.1838 & 0.1760 \\
\hline & 0.01 & 0.0100 & 0.0100 & 0.0100 & 0.0100 & 0.0100 & 0.0100 & 0.0100 & 0.0100 & 0.0100 & 0.0100 \\
\hline \multirow[t]{3}{*}{0.050} & 1.0 & 0.9320 & 0.8404 & 0.7130 & 0.6173 & 0.5477 & 0.4965 & 0.4578 & 0.4031 & 0.3641 & 0.3404 \\
\hline & 0.50 & 0.4881 & 0.4688 & 0.4389 & 0.4145 & 0.3949 & 0.3788 & 0.3653 & 0.3435 & 0.3263 & 0.3124 \\
\hline & 0.25 & 0.2475 & 0.2453 & 0.2431 & 0.2415 & 0.2402 & 0.2392 & 0.2383 & 0.2367 & 0.2353 & 0.2340 \\
\hline 0.10 & 1.0 & 1.000 & 1.000 & 1.000 & 1.000 & 1.000 & 1.000 & 1.000 & 1.000 & 1.000 & 1.000 \\
\hline
\end{tabular}

$P_{1}$ : Restriction on family size; $P_{2}$ : restriction on family number.

$K$. This is consistent with unrestricted selection (Robertson, 1961; Burrows, 1984; Wei and Lindgren, 1991). The two definitions, [1] and [2], are different in value but are related in a way (Kimura and Crow, 1963; Burrows, 1984). The inbreeding coefficient of progeny produced by random mating among selections can be easily obtained using either [1] or [2]. For both of them, two types of approximations give very close results, especially when a strong restriction on family number is used.

Several other factors may influence effective size following selection. For characters with given hereditary ability (heritability), half-sib families have larger withinfamily variation (lower $K$ ) than full-sib families, so they are a better choice for conservation of high effective size. Intense selection (low $P$ ), which is often used for rapid genetic gain in selective breeding, often leads to drastic reductions in effective size (Wei and Lindgren, 1991). Values of $P$ should be deliberately chosen. Table III shows the effects of family number and size on the effective size following selection. While the effective size $\left(N_{R}\right)$ increases significantly with family number, the 
Table II. Predicted effective population size for restricted selection from a population of 20 full-sib families, each of 20 members when $K=0.2\left(K^{*}=0.830\right)$ and $P=0.1$.

\begin{tabular}{|c|c|c|c|c|c|c|c|c|c|}
\hline \multirow[t]{2}{*}{$\mathrm{P}_{1}$} & \multirow[t]{2}{*}{$\mathrm{P}_{2}$} & \multicolumn{4}{|c|}{ Based on phenotypes } & \multicolumn{4}{|c|}{ Based on optimal index values } \\
\hline & & $\mathrm{N}_{R 1}$ & $\mathrm{~N}_{R 2}$ & $\mathrm{~N}_{B 1}$ & $\mathrm{~N}_{B 2}$ & $\mathrm{~N}_{R 1}$ & $\mathrm{~N}_{R 2}$ & $\mathrm{~N}_{B 1}$ & $\mathrm{~N}_{B 2}$ \\
\hline \multirow[t]{4}{*}{1.0} & 1.0 & 9.51 & 9.45 & 24.42 & 24.16 & 3.30 & 3.25 & 7.05 & 6.90 \\
\hline & 0.75 & 8.88 & 8.83 & 22.29 & 22.13 & 3.30 & 3.25 & 7.04 & 6.90 \\
\hline & 0.50 & 7.29 & 7.26 & 17.39 & 17.31 & 3.30 & 3.25 & 7.03 & 6.90 \\
\hline & 0.25 & 4.49 & 4.49 & 9.87 & 9.86 & 3.16 & 3.14 & 6.70 & 6.63 \\
\hline \multirow[t]{4}{*}{0.75} & 1.0 & 9.64 & 9.57 & 24.84 & 24.58 & 3.76 & 3.72 & 8.14 & 7.99 \\
\hline & 0.75 & 8.99 & 8.95 & 22.67 & 22.50 & 3.76 & 3.72 & 8.14 & 7.99 \\
\hline & 0.50 & 7.38 & 7.36 & 17.67 & 17.59 & 3.76 & 3.72 & 8.12 & 7.99 \\
\hline & 0.25 & 4.55 & 4.55 & 10.02 & 10.01 & 3.56 & 3.54 & 7.63 & 7.58 \\
\hline \multirow[t]{4}{*}{0.50} & 1.0 & 9.94 & 9.87 & 25.86 & 25.59 & 5.03 & 4.97 & 11.27 & 11.06 \\
\hline & 0.75 & 9.28 & 9.23 & 23.60 & 23.43 & 5.02 & 4.96 & 11.23 & 11.05 \\
\hline & 0.50 & 7.64 & 7.62 & 18.43 & 18.36 & 5.00 & 4.95 & 11.15 & 11.02 \\
\hline & 0.25 & 4.78 & 4.78 & 10.59 & 10.58 & 4.52 & 4.51 & 9.94 & 9.91 \\
\hline \multirow[t]{3}{*}{0.25} & 1.0 & 11.76 & 11.70 & 32.56 & 32.28 & 8.95 & 8.87 & 22.54 & 22.23 \\
\hline & 0.75 & 11.04 & 11.00 & 29.75 & 29.60 & 8.88 & 8.82 & 22.30 & 22.07 \\
\hline & 0.50 & 9.20 & 9.19 & 23.29 & 23.26 & 8.66 & 8.64 & 21.56 & 21.49 \\
\hline
\end{tabular}

It is assumed that family means and within-family deviations are normally distributed, and the total phenotypic variance is one. $N_{R 1}$ and $N_{R 2}$ are approximations ([12] and [18] respectively) to Robertson's effective size; $N_{B 1}$ and $N_{B 2}$ are approximations ([14] and [20] respectively) to Burrow's effective size.

increase with family size is trivial. This suggests that if effective size is of concern, having many families in breeding populations is more important.

Because selection is totally at random when $K=0$, a drift effect due to small family size is included in the approximations of effective size (eqs [12], [14], [18] and [20]). Small differences between $N_{R}$ and $N_{R 2}$ (or $N_{B}$ and $N_{B 2}$ ) (table II) may be explained by the decreasing influences of $K$ on drift effect as it approaches one (Wei and Lindgren, 1994, 1996). The approximation (eqs [12] and [14]) yield the exact values when $K=0$ and $m \rightarrow \infty$ (Burrows, 1984; Woolliams, 1989). This is also true for [18] and [20]. Moreover [18] and [20] give the exact value at $K=1$. It has been found that the approximations for unrestricted selection underestimate effective size when $K>0$ and family number is small (Woolliams, 1989). Computer simulation shows (table IV) that restriction (both $P_{1}$ and $P_{2}$ ) greatly improves the prediction of effective size. Increasing family number could also better the prediction at a given family size, although large family size has a negative effect (table IV). The quantity $N_{r}\left(K, P, P_{1}, P_{2}\right)$ is a limiting result for large family number $(m)$. The prediction of effective size for small $m$ could then be improved by the adjustment of $N_{r}\left(K, P, P_{1}, P_{2}\right)$, denoted by $N_{r}^{*}\left(K, P, P_{1}, P_{2}\right)$, according to Burrows (1984).

$N_{r}^{*}\left(K, P, P_{1}, P_{2}\right)=m P_{2} N_{r}\left(K, P, P_{1}, P_{2}\right) /\left[(m-1) P_{2}+N_{r}\left(K, P, P_{1}, P_{2}\right)\right], m \geqslant 1 / P_{2}$ 
Table III. Predicted effective sizes $\left(N_{R 2}\right)$ under restricted selection from full-sib families for two family numbers $(m)$, family sizes $(s)$ and ratios $(K)$ of family mean variance to the total variance.

\begin{tabular}{|c|c|c|c|c|c|c|c|c|c|}
\hline \multirow[t]{3}{*}{$\mathrm{P}_{1}$} & \multirow[t]{3}{*}{$\mathrm{P}_{2}$} & \multicolumn{4}{|c|}{$\mathrm{s}=40$} & \multicolumn{4}{|c|}{$\mathrm{s}=40$} \\
\hline & & \multicolumn{2}{|c|}{$\mathrm{m}=20$} & \multicolumn{2}{|c|}{$m=40$} & \multicolumn{2}{|c|}{$\mathrm{m}=20$} & \multicolumn{2}{|c|}{$\mathrm{m}=40$} \\
\hline & & $\mathrm{s} 1$ & $\mathrm{~s} 2$ & $\mathrm{~s} 1$ & $\mathrm{~s} 2$ & s 1 & $\mathrm{~s} 2$ & $\mathrm{~s} 1$ & s2 \\
\hline 1.0 & $\begin{array}{l}1.0 \\
0.50 \\
0.25\end{array}$ & $\begin{array}{r}\quad(K \\
9.20 \\
6.93 \\
4.27\end{array}$ & $\begin{array}{l}0.25 \\
1.78 \\
1.78 \\
1.76\end{array}$ & $\begin{array}{r}K^{*}=0 . \\
18.16 \\
13.70 \\
8.45\end{array}$ & $\begin{array}{l}23) \\
3.48 \\
3.48 \\
3.45\end{array}$ & $\begin{array}{r}(K \\
10.24 \\
7.44 \\
4.42\end{array}$ & $\begin{array}{l}.15 \\
1.83 \\
1.82 \\
1.80\end{array}$ & $\begin{array}{c}{ }^{*}=0.8 \\
20.22 \\
14.76 \\
8.78\end{array}$ & $\begin{array}{l}3 \text { ) } \\
3.57 \\
3.56 \\
3.53\end{array}$ \\
\hline 0.50 & $\begin{array}{l}1.0 \\
0.50 \\
0.25\end{array}$ & $\begin{array}{l}9.38 \\
7.07 \\
4.35\end{array}$ & $\begin{array}{l}2.71 \\
2.70 \\
2.65\end{array}$ & $\begin{array}{r}18.53 \\
13.99 \\
8.64\end{array}$ & $\begin{array}{l}5.31 \\
5.29 \\
5.22\end{array}$ & $\begin{array}{r}10.34 \\
7.52 \\
4.47\end{array}$ & $\begin{array}{l}2.76 \\
2.74 \\
2.68\end{array}$ & $\begin{array}{r}20.44 \\
14.93 \\
8.89\end{array}$ & $\begin{array}{l}5.39 \\
5.38 \\
5.29\end{array}$ \\
\hline 0.25 & $\begin{array}{l}1.0 \\
0.50 \\
0.25\end{array}$ & $\begin{array}{l}9.89 \\
7.52 \\
4.76\end{array}$ & $\begin{array}{l}4.83 \\
4.76 \\
4.44\end{array}$ & $\begin{array}{r}19.56 \\
14.93 \\
9.50\end{array}$ & $\begin{array}{l}9.50 \\
9.39 \\
8.85\end{array}$ & $\begin{array}{r}10.74 \\
7.87 \\
4.80\end{array}$ & $\begin{array}{l}4.91 \\
4.82 \\
4.47\end{array}$ & $\begin{array}{r}21.23 \\
15.65 \\
9.59\end{array}$ & $\begin{array}{l}9.64 \\
9.52 \\
8.91\end{array}$ \\
\hline 0.125 & $\begin{array}{l}1.0 \\
0.50\end{array}$ & $\begin{array}{r}11.89 \\
9.19\end{array}$ & $\begin{array}{l}8.86 \\
8.57\end{array}$ & $\begin{array}{l}23.58 \\
18.34\end{array}$ & $\begin{array}{l}17.52 \\
17.08\end{array}$ & $\begin{array}{r}12.62 \\
9.35\end{array}$ & $\begin{array}{l}9.00 \\
8.65\end{array}$ & $\begin{array}{l}25.03 \\
18.67\end{array}$ & $\begin{array}{l}17.76 \\
17.23\end{array}$ \\
\hline 1.0 & $\begin{array}{l}1.0 \\
0.50 \\
0.25\end{array}$ & $\begin{array}{r}\quad(K \\
6.30 \\
5.48 \\
3.83\end{array}$ & $\begin{array}{l}0.3 \\
2.45 \\
2.44 \\
2.32\end{array}$ & $\begin{array}{c}*=0.7 \\
12.39 \\
10.81 \\
7.57\end{array}$ & $\begin{array}{l}4.80 \\
4.78 \\
4.57\end{array}$ & $\begin{array}{r}(K \\
6.74 \\
5.79 \\
3.94\end{array}$ & $\begin{array}{l}0.3 \\
2.56 \\
2.54 \\
2.40\end{array}$ & $\begin{array}{r}=0.7 \\
13.25 \\
11.43 \\
7.82\end{array}$ & $\begin{array}{l}\text { 4) } \\
5.00 \\
4.98 \\
4.73\end{array}$ \\
\hline 0.50 & $\begin{array}{l}1.0 \\
0.50 \\
0.25\end{array}$ & $\begin{array}{l}6.50 \\
5.66 \\
3.97\end{array}$ & $\begin{array}{l}3.23 \\
3.21 \\
3.01\end{array}$ & $\begin{array}{r}12.78 \\
11.18 \\
7.87\end{array}$ & $\begin{array}{l}6.33 \\
6.30 \\
5.95\end{array}$ & $\begin{array}{l}6.89 \\
5.92 \\
4.06\end{array}$ & $\begin{array}{l}3.32 \\
3.29 \\
3.07\end{array}$ & $\begin{array}{r}13.56 \\
11.71 \\
8.06\end{array}$ & $\begin{array}{l}6.50 \\
6.47 \\
6.07\end{array}$ \\
\hline 0.25 & $\begin{array}{l}1.0 \\
0.50 \\
0.25\end{array}$ & $\begin{array}{l}7.62 \\
6.66 \\
4.70\end{array}$ & $\begin{array}{l}5.28 \\
5.17 \\
4.53\end{array}$ & $\begin{array}{r}15.02 \\
13.19 \\
9.37\end{array}$ & $\begin{array}{r}10.35 \\
10.22 \\
9.03\end{array}$ & $\begin{array}{l}8.01 \\
6.89 \\
4.73\end{array}$ & $\begin{array}{l}5.39 \\
5.29 \\
4.57\end{array}$ & $\begin{array}{r}15.78 \\
13.66 \\
9.45\end{array}$ & $\begin{array}{r}10.61 \\
10.45 \\
9.11\end{array}$ \\
\hline 0.125 & $\begin{array}{l}1.0 \\
0.50\end{array}$ & $\begin{array}{r}10.63 \\
9.06\end{array}$ & $\begin{array}{l}9.11 \\
8.73\end{array}$ & $\begin{array}{l}21.05 \\
18.06\end{array}$ & $\begin{array}{l}18.09 \\
17.41\end{array}$ & $\begin{array}{r}11.07 \\
9.19\end{array}$ & $\begin{array}{l}9.31 \\
8.84\end{array}$ & $\begin{array}{l}21.90 \\
18.35\end{array}$ & $\begin{array}{l}18.43 \\
17.62\end{array}$ \\
\hline
\end{tabular}

It is assumed that family means and within-family deviations are normally distributed, the total phenotypic variance is one and the selected proportion $(P)$ is 0.05 . s1: Selection based on phenotypes; $s 2$ : selection based on optimal index values.

which is bounded at $P_{2}$ as $N_{r}\left(K, P, P_{1}, P_{2}\right)=P_{2}$, especially $N_{r}^{*}\left(K, P, P_{1}, P_{2}\right)=$ $P_{2}=1$ as $m=1$. 
Table IV. Comparison of predicted $\left(N_{R 1}\right)$ and simulated $\left(N_{R s}\right)$ effective population sizes on varying $P_{1}, P_{2}, m$ or $s$ while other parameters are kept constant.

\begin{tabular}{llccc}
\hline & \multicolumn{3}{c}{$\mathrm{N}_{\mathrm{R} 1}\left(\mathrm{~N}_{\mathrm{Rs}} / C V\right)$} \\
\hline$K=0.2$ & $m=20 \quad s=20$ & $P_{1}=1$ & $P_{1}=0.5$ & $P_{1}=0.25$ \\
$P=0.1$ & $P_{2}=0.5$ & $7.29(7.52 / 0.122)$ & $7.64(7.61 / 0.104)$ & $9.20(9.13 / 0.029)$ \\
$K=0.2 \quad m=20 \quad s=20$ & $P_{2}=1$ & $P_{2}=0.5$ & $P_{2}=0.25$ \\
$P=0.1 \quad P_{1}=0.5$ & $9.94(10.14 / 0.165)$ & $7.64(7.61 / 0.104)$ & $4.78(4.75 / 0.024)$ \\
$K=2 \quad m=20 \quad P=0.05$ & $s=20$ & $s=40$ & $s=60$ \\
$P_{1}=0.5 \quad P_{2}=0.5$ & $5.91(6.09 / 0.188)$ & $6.54(6.88 / 0.170)$ & $6.77(7.08 / 0.163)$ \\
$K=0.2 \quad s=20 \quad P=0.05$ & $m=20$ & $m=40$ & $m=60$ \\
$P_{1}=0.5 \quad P_{2}=0.5$ & $5.91(6.09 / 0.188)$ & $11.67(11.77 / 0.149)$ & $17.43(17.40 / 0.122)$ \\
\hline
\end{tabular}

The simulated effective sizes, $N_{R s}$ are the averaged values over 500 runs of simulations, and $\mathrm{CV}$ are the corresponding variable coefficients.

\section{ACKNOWLEDGMENTS}

I am indebted to D Lindgren for encouragement and helpful comments, and $\mathbf{J}$ Blackwell for revising the English text. This study has been supported by Skogsindustrins Forskningsstiftelse.

\section{REFERENCES}

Burrows PP (1984) Inbreeding under selection from unrelated families. Biometrics 40, 357-366

Falconer DS (1989) An Introduction to Quantitative Genetics (3rd edition), Longman Scientific and Technical, London, UK

Kimura M, Crow JF (1963) The measurement of effective population number. Evolution $17,279-288$

Lush JL (1947) Family merit and individual merit as bases for selection. Am Nat 81, 241-261; 262-379

Robertson A (1961) Inbreeding in artificial selection programmes. Genet Res 2, 189-194

Wei RP (1995) Optimal restricted phenotypic selection. Theor Appl Genet 91, 389-394

Wei RP, Lindgren D (1991) Selection effects on diversity and genetic gain. Silva Fenn 25, 229-234

Wei RP, Lindgren D (1994) Gain and effective population size following index selection with variable weights. For Genet 1, 147-155

Wei RP, Lindgren D (1996) Effective family number following selection with restrictions. Biometrics 52, 198-208

Woolliams JA (1989) Modifications to MOET nucleus breeding schemes to improve rates of genetic progress and decrease rates of inbreeding in dairy cattle. Anim Prod 49, 1-14 


\section{APPENDIX}

Restricted selection is applied to the $m_{r} s_{r}\left(=m s P_{1} P_{2}\right)$ individuals shortlisted by considering both restrictions. Those with the highest performances are truncated at the point $x_{\mathrm{T}}$, corresponding to $P, P_{1}$ and $P_{2}$. Assume that the family mean, $x_{j}=x$, is a continuous random variable with a density function $f(x)$. The truncation point for a particular family with mean value $x$ on a standardized scale is expressed as $y=\left(x_{\mathrm{T}}-x\right) / \sigma_{w}$. Let $F$ denote the unit distribution function. In the $j$ th family with $x_{j}=x$, the probability that the performance of an individual exceeds $x_{\mathrm{T}}$ is $[1-F(y)] / P_{1}$, and the probability that the performance is less than $x_{\mathrm{T}}$ is $\left.\left[F(y)+P_{1}-1\right)\right] / P_{1}$. We can reasonably assume that $1-F(y)=0$ and $F(y)=1$ for the $m-m_{r}$ rejected families. Then the probability that in the $j$ th family, $U_{j}(=u)$ individuals have a value greater than $x_{\mathrm{T}}$ and $s_{r}-u$ have a value less than $x_{\mathrm{T}}$, $p_{u}=\operatorname{pr}\left(U_{j}=u\right)$ is given by integrating over the distribution of $x$ (Burrows, 1984) in the form

$$
p_{u}=\left(\begin{array}{c}
s_{r} \\
u
\end{array}\right)[F(y)]^{s_{r}-u}[1-F(y)]^{u} f(x) d x
$$

where the integral part is the expectation with respect to the family mean $x$. Thus, the moment-generating function for $U_{j}$ is

$$
M(\theta)=\sum_{u=0}^{s_{r}} \mathrm{e}^{\theta u} p_{u}=\int\left\{F(y)+\mathrm{e}^{\theta}[1-F(y)]\right\}^{s_{r}} f(x) d x
$$

The expectations of $U_{j}$ and $U_{j}^{2}$ are given by the values of the first and second derivatives of $M(\theta)$ at $\theta=0$ :

$$
E\left(U_{j}\right)=M^{\prime}(0)=s_{r} \int\left\{[1-F(y)] / P_{1}\right\} f(x) d x=s P
$$

and

$$
\begin{gathered}
E\left(U_{j}^{2}\right)=M^{\prime \prime}(0)=s_{r}\left(s_{r}-1\right) \int\left\{[1-F(y)] / P_{1}\right\}^{2} f(x) d x+E\left(U_{j}\right)= \\
s\left(s P_{1}-1\right) P^{2} / P_{1} N_{r}\left(K, P, P_{1}, P_{2}\right)+s P= \\
s P\left[s P P_{1}+P_{1} N_{r}\left(K, P, P_{1}, P_{2}\right)-P\right] /\left[P_{1} N_{r}\left(K, P, P_{1} P_{2}\right)\right]
\end{gathered}
$$

Similarly we can obtain the probability generating function for $U_{j}$ :

$$
P(\theta)=\sum_{u=0}^{s_{r}} \theta^{u} p_{u}=\int\{F(y)+\theta[1-F(y)]\}^{s_{r}} f(x) d x,|\theta| \leqslant 1
$$

The expectation of $U_{j}\left(U_{j}-1\right)$ is given by the value of the second derivatives of $P(\theta)$ at $\theta=1$ :

$$
\begin{aligned}
E\left[U_{j}\left(U_{j}-1\right)\right]=P^{\prime \prime}(1)=s_{r}\left(s_{r}-1\right) \int\left\{[1-F(y)] / P_{1}\right\}^{2} f(x) d x= \\
s\left(s P_{1}-1\right) P^{2} / P_{1} N_{r}\left(K, P, P_{1}, P_{2}\right)
\end{aligned}
$$

